\title{
Evaluation of pre-natal care from the perspective of different models in primary care ${ }^{1}$
}

\author{
Renata Leite Alves de Oliveira ${ }^{2}$ \\ Cátia Regina Branco da Fonseca ${ }^{3}$ \\ Maria Antonieta de Barros Leite Carvalhaes ${ }^{3}$ \\ Cristina Maria Garcia de Lima Parada ${ }^{4}$
}

\begin{abstract}
Objectives: to evaluate the quality of the pre-natal care delivered in primary care, comparing the traditional model and the Family Health Strategy. Method: a service evaluation study, grounded in the public health policies. The data was obtained from interviews with managers, observation in the health centers, and analysis of patient records of pregnant women, selected at random. Differences in the indicators for structure and process were evaluated using the Chi-squared test, adopting $\mathrm{p}<0.05$ as the critical value, calculation of the odds ratio, and confidence intervals of 95\%. Results: Similar structures were evidenced in both models of care. Synthesis indicators for the process created in the present study, and those indicated by the public policies, indicated that the situation is more favorable in Family Health Centers. Regarding the set of activities called for in pre-natal care, the performance was flawed in both models, although it was slightly better in the Family Health Centers. Conclusion: the results indicate the need for actions to improve prenatal care in the two models of primary care evaluated in the municipality.

Descriptors: Evaluation of Health Care Programs and Projects; Prenatal Care; Primary Health Care.
\end{abstract}

\footnotetext{
${ }^{1}$ Paper extracted from Master's Thesis "Avaliação da Assistência pré-natal no município de Botucatu-SP na perspectiva dos diferentes modelos de atenção" presented to Faculdade de Medicina de Botucatu, Universidade Estadual Paulista "Júlio de Mesquita Filho", Botucatu, SP, Brazil. 2 RN, MSc, Secretaria Municipal de Saúde de Botucatu, Botucatu, SP, Brazil.

${ }^{3}$ PhD, Assistant Professor, Faculdade de Medicina de Botucatu, Universidade Estadual Paulista "Júlio de Mesquita Filho", Botucatu, SP, Brazil.

${ }^{4}$ PhD, Adjunct Professor, Faculdade de Medicina de Botucatu, Universidade Estadual Paulista "Júlio de Mesquita Filho", Botucatu, SP, Brazil.
}

Corresponding Author:

Cristina Maria Garcia de Lima Parada

Universidade Estadual Paulista "Júlio de Mesquita Filho"

Faculdade de Medicina de Botucatu

Campus Universitário de Rubião Júnior, $\mathrm{s} / \mathrm{n}$

Bairro: Rubião Júnior

CEP: 18618-970, Botucatu, SP, Brasil

E-mail: cparada@fmb.unesp.br 


\section{Introduction}

Pre-natal care is one of the main constituents of the Unified Health Service's (SUS) Primary Care Pact and there are formal indicators for its monitoring. The form in which it is carried out may be indicative of the quality of the health services ${ }^{(1)}$ and, therefore, an assessment of it which considers whether it was undertaken in a center using the traditional model, or in a Family Health Center, can, consequently, evaluate the care model itself.

The health care carried out in the primary care centers which follow the traditional model is, in general, centered on the presence of specialists, each one of whom is responsible for problems related to the particular area where they work. With its work process often centered on the doctor, in the curative model of care, one can frequently observe, in addition to the overloading to which these professionals are often exposed, the compromising of preventive actions and health promotion actions, both of which are essential in pre-natal care ${ }^{(2)}$.

In order to improve on this model, in 1994 the Ministry of Health (MS) proposed the Family Health Strategy (ESF), whose principal objective is to reorganize health care practice on new bases and replace the traditional model, integrally and continually prioritizing actions of prevention and actions for the promotion and recovery of people's health. The care is provided in health centers or in the home, by the professional who make up the Family Health teams. It is hoped that health professionals and the population will build links of co-responsibility, facilitating the identification of and attendance to the community's health problems ${ }^{(3)}$.

It is important to evaluate the quality of prenatal care due to its potential for avoiding infant ${ }^{(4)}$ and maternal deaths. Hence, the present study aimed to evaluate the quality of the pre-natal care for the lowrisk pregnancy, given in primary care, comparing the traditional model and the Family Health Strategy.

The methodological framework for evaluation adopted was proposed in the 1980's by Donabedian, for whom studying the process is the best way of investigating the quality and content of the care offered in primary health care ${ }^{(5)}$, because of which this shall be the focus of the present study.

\section{Material and Method}

This is a descriptive study, inserted in the field of epidemiology directed at assessing the health services. The resources (physical, human and material) existing (structure) and the process of pre-natal care provided in the Primary Health Centers (UBS), which follow the traditional model, and in the Family Health Centers (USF), were evaluated.

As the theoretical framework for analyzing the data, the National Policy for Integral Attention to Women's Health(6) - specifically, relative to the care pathway for the pregnant woman - the assumptions of the Program for the Humanization of Pre-Natal stage, Labor and Birth (PHPN) $^{(7)}$ and the State of São Paulo Technical Manual for Pre-Natal and Post-Natal Care ${ }^{(8)}$ were adopted.

The investigation was undertaken in the municipality of Botucatu, situated in the Central-Southern region of the state of São Paulo, with a population estimated at 127,328 inhabitants ${ }^{(9)}$, and which falls under the VI Regional Health Department - Bauru. Under the SUS, for providing primary health care, it has eight UBS and eight USF, and for childbirth, it has one maternity hospital which takes care of low-risk pregnancies, and one center of excellence for high risk pregnancies.

For analysis of the structure, all sixteen primary care centers were studied. For analysis of the process, the target population was composed of all the women registered in the Pre-Natal Information System (SISPRENATAL) in 2009: 1082 pregnant women. The sample calculation was made taking into account a maximum prevalence of $50 \%$, a confidence interval of $95 \%$, and a margin of error of $5 \%$, resulting in 282 pregnant women, of whom 115 were attended in the USF, and 167 in the UBS. These were selected at random and in proportion to the numbers registered in each health center.

Pregnant women who had started the pre-natal care in primary health care centers were included, who were up to the twentieth week of pregnancy and who remained considered as low risk pregnancies, not needing to be referred to the high risk pregnancy service. To ensure the established sample size, a surplus of $20 \%$ of pregnant women was chosen at random in each center.

To characterize the structure available for the prenatal care, indicators relating to the human resources were considered: the training of the health professionals, training undertaken in the area, and participation/ attendance in pregnant women's groups; physical resources: rooms for attending patients, individually or 
in groups; material resources and equipment: availability of the pre-natal card* and instrument for recording the clinical history and the identification of risk, furniture, essential medications, care protocols, and basic material (sheets, weight-height measuring scales, stethoscopes, sphygmomanometer, Doppler ultrasound equipment, tape measures and material for collection of oncotic colpocytology).

For the analysis of pre-natal care, indicators from the PHPN and the State of São Paulo Technical Manual for Pre-Natal and Post-Natal Care ${ }^{(7-8)}$ were used: start at up to 17 weeks; minimum of six consultations (one in the first trimester, two in the second, and three in the third); measurement of fundal height; carrying out the set of tests recommended for the first trimester (blood typing, serology for toxoplasmosis, AIDS, syphilis, and Hepatitis B, stool parasite test, hemogram, basic urine test or urine cultures and fasting blood glucose test) and for the third trimester (serology for syphilis and AIDS and for toxoplasmosis and Hepatitis B if necessary, basic urine test or urine culture and fasting blood glucose test); collection of oncotic colpocytology; anti-tetanus vaccination and participation in the pregnant women's group.

Seeking a qualitative evaluation of the content of the consultations carried out, records of the following aspects were also observed in the patients' health records: existence of guidance on diet and on the warning signs according to the stage of the pregnancy, referral for dental treatment; clinical examination of the breasts and the prescription of ferrous sulphate.

All the aspects were checked dichotomously: yes or no, for each pregnant woman. Later, synthesis indicators were created: all the tests of the first trimester; all the tests of the third trimester; all the tests of the first and third trimesters; six consultations and tests; six consultations and postpartum care; six consultations, tests and postpartum care; six consultations, tests, anti-tetanus vaccination and postpartum care; blood pressure, weight and fundal height in all the consultations; nutritional guidance and warning signs for the stage of the pregnancy; complete clinical history and anti-HIV counselling.

Two instruments using closed questions were developed for the data collection, which was accomplished in 2010 and 2011 by two people, previously trained. The first instrument was used in interviews with the managers and to guide the observation in the health centers, and contained information about the structure available. The second referred to the care process and was used for collecting the information required from the pregnant women's health records.

For quality control, at the end of the data collection, $10 \%$ of the patients' health records were chosen at random for conference, and it was concluded that the collection had been adequate.

The statistical software Epi-Info 6.0 was used for analysis of the data. Data relative to the structure was presented based in descriptive statistics; the Chisquared test $\left(\chi^{2}\right)$ was used for evaluating the differences of quality of the pre-natal care process between the UBS and the USF, fixing a level of significance of $\alpha=0.05$, with calculation of the odds ratio and respective confidence intervals (CI) at $95 \%$.

This study was assessed and approved by the local Research Ethics Committee (Decision no 184/2010) and respected all the norms of research involving human beings.

\section{Results}

In the UBS, all the doctors who attended during the pre-natal stage were gynecologists-obstetricians, while in the USF, the specialities of General Practice and Family Health predominated. Among the specialist nurses, the area of Family Health stood out, in a quarter of the UBS and more than half of the USF. Social workers who were part of the Mental Health Team and dentists and psychologists in the health centers regularly attended the pregnant women, both in the UBS and the USF, while the nutritionist was available only in the UBS. Pregnant women's groups were held in the same proportion in the UBS and the USF (75.0\%), with a wide variety in the regularity (weekly or every two months). All the nurses of the two models participated in these groups, with doctors participating less frequently: two cases in the USF (16.7\%) and four cases in the UBS (36.4\%). None of the UBS dentists and three (30\%) from the USF participated in the activities, as did two (66.7\%) nutritionists who worked in the UBS. Four continuing education activities focussing on pre-natal care were mentioned and, in a general way, professionals from the USF had more opportunities to participate than those from the UBS. Such data concerning structure are not presented in the Tables.

The physical resources were adequate and similar in the UBS and the USF. The great majority of the necessary materials were also available in both the models, apart

*A card containing data from visits for check-ups during the pregnancy. Translator's note. 
from the 2010 State of São Paulo Technical Manual for Pre-Natal and Post-Natal Care ${ }^{(7)}$, and some essential medications, absent in some of the UBS and USF.

The analysis of the process evidenced that of the pregnant women attended, $93.4 \%$ had initiated the prenatal care up to the 17 th week in the UBS, and $86.0 \%$ had in the USF (difference in the limit of statistical significance). In the USF, the nursing consultations occurred more, while in the UBS there were more consultations with doctors, a statistically-significant difference (Table 1).

Table 1 - Distribution of the pregnant women in the USF $(n=115)$ and UBS $(n=167)$ according to process indicators relative to the consultations and period when they took place. Botucatu, SP, Brazil, 2010

\begin{tabular}{|c|c|c|c|c|c|c|}
\hline \multirow{2}{*}{ Consultations } & \multicolumn{2}{|c|}{ USF } & \multicolumn{2}{|c|}{ UBS } & \multirow{2}{*}{$p$ value } & \multirow{2}{*}{ OR (Cl) } \\
\hline & $\mathbf{N}$ & $\%$ & $\mathbf{N}$ & $\%$ & & \\
\hline First $<17$ weeks & 99 & 86.0 & 156 & 93.4 & 0.039 & $0.44(0.18-1.04)$ \\
\hline One in $1^{\text {st }}$ trimester & 81 & 70.4 & 132 & 79.1 & 0.098 & $0.63(0.35-1.13)$ \\
\hline Two in $2^{\text {nd }}$ trimester & 113 & 98.2 & 165 & 98.8 & $0.705^{*}$ & $0.68(0.07-6.91)$ \\
\hline Three in $3^{\text {rd }}$ trimester & 109 & 94.8 & 154 & 92.2 & 0.398 & $1.53(0.52-4.69)$ \\
\hline Minimum of six & 108 & 94.0 & 162 & 97.0 & 0.206 & $0.48(0.13-1.72)$ \\
\hline By nurses & & & & & 0.000 & $0.01(0.00-0.02)$ \\
\hline Up to 3 & 9 & 7.8 & 156 & 93.4 & & \\
\hline 4 or more & 106 & 92.2 & 11 & 6.6 & & \\
\hline By doctors & & & & & $0.000^{*}$ & $240.17(34.55-4778.23)$ \\
\hline Up to 3 & 68 & 59.0 & 1 & 0.6 & & \\
\hline 4 or more & 47 & 41.0 & 166 & 99.4 & & \\
\hline
\end{tabular}

In the first trimester of the pregnancy, the women attended in the USF undertook significantly more indirect Coombs tests and serology for Hepatitis $B$, while the same was true in the UBS for the stool parasite test. In the third trimester, the pregnant women in the USF did the blood glucose tests, hemograms, indirect Coombs tests, basic urine tests or urine culture and serologies: syphilis, toxoplasmosis and Hepatitis B significantly more than in the UBS (Table 2).

Table 2 - Distribution of tests undertaken in the first and third trimesters by the pregnant women in the USF ( $n=115$ ) and UBS $(n=167)$ during the pre-natal care. Botucatu, SP, Brazil, 2010

\begin{tabular}{|c|c|c|c|c|c|c|}
\hline \multirow{2}{*}{ Tests } & \multicolumn{2}{|c|}{ USF } & \multicolumn{2}{|c|}{ UBS } & \multirow{2}{*}{$p$ value } & \multirow{2}{*}{ OR (CI) } \\
\hline & $\mathbf{N}$ & $\%$ & $\mathbf{N}$ & $\%$ & & \\
\hline \multicolumn{7}{|l|}{ First trimester } \\
\hline Blood Typing ABO/Rh & 111 & 96.5 & 160 & 95.8 & 0.761 & $1.21(0.31-5.07)$ \\
\hline Hemogram & 113 & 98.3 & 165 & 98.8 & 0.705 & $0.68(0.07-6.91)$ \\
\hline Serology for syphilis & 112 & 97.4 & 159 & 95.2 & 0.352 & $1.88(0.44-9.15)$ \\
\hline HIV test & 111 & 96.5 & 164 & 98.2 & 0.071 & $0.17(0.01-1.61)$ \\
\hline Fasting Blood Glucose test & 115 & 100.0 & 166 & 99.4 & 0.405 & - \\
\hline Basic urine test or urine culture & 110 & 95.6 & 159 & 95.2 & 0.861 & $1.11(0.32-4.01)$ \\
\hline Indirect Coombs & 104 & 90.4 & 128 & 77.0 & 0.028 & $2.88(1.34-6.30)$ \\
\hline Serology for toxoplasmosis & 113 & 98.2 & 158 & 94.6 & 0.119 & $3.22(0.63-22.00)$ \\
\hline Stool parasite test & 56 & 48.7 & 118 & 70.6 & 0.000 & $0.39(0.23-0.67)$ \\
\hline Serology for Hepatitis B & 114 & 99.2 & 155 & 92.8 & 0.012 & $8.83(1.17-184.29)$ \\
\hline Oncotic cytology & 108 & 94.0 & 145 & 86.8 & 0.054 & $2.34(0.91-6.28)$ \\
\hline \multicolumn{7}{|l|}{ Third trimester } \\
\hline Hemogram & 106 & 92.0 & 133 & 79.6 & 0.004 & $3.01(1.31-7.09)$ \\
\hline Serology for syphilis & 104 & 90.4 & 133 & 79.6 & 0.014 & $2.42(1.11-5.34)$ \\
\hline HIV test & 100 & 86.9 & 134 & 80.2 & 0.140 & $1.64(0.81-3.36)$ \\
\hline Fasting Blood Glucose test & 104 & 90.4 & 101 & 60.4 & 0.000 & $6.18(2.96-13.19)$ \\
\hline Basic urine or culture & 103 & 89.5 & 96 & 57.4 & 0.000 & $6.35(3.11-13.19)$ \\
\hline Serology for toxoplasmosis & 107 & 93.0 & 131 & 78.4 & 0.000 & $3.68(1.56-8.98)$ \\
\hline Serology for Hepatitis B & 83 & 72.1 & 92 & 55.0 & 0.003 & $2.11(1.23-3.64)$ \\
\hline Indirect Coombs if Rh- (USF $n=15$ and UBS $n=35)$ & 6 & 40.0 & 3 & 8.0 & 0.024 & $7.11(1.21-46.38)$ \\
\hline
\end{tabular}


Some aspects indicative of the quality of the pre-natal care are described in Table 3. Pregnant women attended in the USF had significantly more records of fundal height in all the consultations, clinical histories completely filled out, guidance on nutrition and on the warning signs according to the stage of the pregnancy, dental care and prescription of ferrous sulphate.

Table 3 - Aspects indicative of quality in pre-natal care for the pregnant women attended in the USF $(n=115)$ and UBS $(n=167)$. Botucatu, SP, Brazil, 2010

\begin{tabular}{|c|c|c|c|c|c|c|}
\hline \multirow{2}{*}{ Variable } & \multicolumn{2}{|c|}{ USF } & \multicolumn{2}{|c|}{ UBS } & \multirow{2}{*}{$p$ value } & \multirow{2}{*}{ OR (Cl) } \\
\hline & $\mathbf{N}$ & $\%$ & $\mathbf{N}$ & $\%$ & & \\
\hline Blood pressure* & 114 & 99.1 & 166 & 99.4 & 0.790 & $0.69(0.02-25.58)$ \\
\hline Weight* & 114 & 99.1 & 167 & 100.0 & 0.227 & $0.00(0.00-11.97)$ \\
\hline Fundal height* & 112 & 97.3 & 145 & 86.0 & 0.002 & $5.66(1.56-24.41)$ \\
\hline Complete clinical history & 23 & 20.0 & 4 & 2.0 & 0.000 & $10.19(3.21-35.96)$ \\
\hline Ultrasonography & 105 & 91.3 & 156 & 93.4 & 0.507 & $0.74(0.28-1.96)$ \\
\hline Vaccination against tetanus & 95 & 82.6 & 129 & 77.2 & 0.273 & $1.40(0.74-2.67)$ \\
\hline Warning signs according to stage of pregnancy & 107 & 93.0 & 91 & 54.5 & 0.000 & $11.17(4.89-26.49)$ \\
\hline HIV counselling & 10 & 8.6 & 7 & 4.2 & 0.118 & $2.18(0.74-6.57)$ \\
\hline Nutritional guidance & 107 & 93.0 & 85 & 51.0 & 0.000 & $12.9(5.65-30.59)$ \\
\hline Dental care & 53 & 46.1 & 54 & 32.3 & 0.019 & $1.79(1.06-3.01)$ \\
\hline Breast examination & 54 & 46.9 & 63 & 37.7 & 0.122 & $1.46(0.88-2.44)$ \\
\hline Prescription of ferrous sulphate & 115 & 100.0 & 154 & 92.2 & 0.002 & - \\
\hline Early postpartum care & 8 & 7.0 & 5 & 3.0 & 0.118 & $2.42(0.70-8.78)$ \\
\hline Late postpartum care & 67 & 58.2 & 104 & 62.2 & 0.497 & $0.85(0.51-1.41)$ \\
\hline
\end{tabular}

*In all consultations

Synthesis indicators for the process appear in Table 4.

The situation in the USF was significantly more favorable when one considers: tests in third trimester; tests in first and third trimesters; six consultations and tests; six consultations, tests, and postpartum care; six consultations, tests, postpartum care and vaccination against tetanus; recording of blood pressure, weight and fundal height in all consultations; nutritional guidance, guidance on the warning signs according to the stage of the pregnancy; clinical history completely filled out and counselling prior to the collection of the blood sample for the HIV test. (Table 4).

Table 4 - Synthesis indicators for the pre-natal care process, considering the USF $(n=115)$ and UBS $(n=167)$. Botucatu, SP, Brazil, 2010

\begin{tabular}{|c|c|c|c|c|c|c|}
\hline \multirow{2}{*}{ Indicator } & \multicolumn{2}{|c|}{ USF } & \multicolumn{2}{|c|}{ UBS } & \multirow{2}{*}{$p$ value } & \multirow{2}{*}{ OR (Cl) } \\
\hline & $\mathbf{N}$ & $\%$ & $\mathbf{N}$ & $\%$ & & \\
\hline Tests of $1^{\text {st }}$ trimester & 101 & 87.8 & 142 & 85 & 0.503 & $1.27(0.60-2.72)$ \\
\hline Tests of $3^{\text {rd }}$ trimester & 96 & 83.5 & 59 & 35.3 & 0.000 & $9.25(4.97-17.38)$ \\
\hline Tests of $1^{\text {st }}$ and $3^{\text {rd }}$ trimesters & 87 & 75.7 & 53 & 31.7 & 0.000 & $6.68(3.78-11.87)$ \\
\hline 6 consultations* & 77 & 67 & 119 & 71 & 0.440 & $0.82(0.47-1.41)$ \\
\hline 6 consultations $^{*}$ and tests & 64 & 55.6 & 38 & 22.7 & 0.000 & $4.26(2.46-7.39)$ \\
\hline 6 consultations $^{*}$ and postpartum care & 49 & 42.6 & 77 & 46.1 & 0.521 & $0.87(0.52-1.44)$ \\
\hline 6 consultations*, tests and postpartum care & 41 & 35.7 & 22 & 13.2 & 0.000 & $3.65(1.95-6.97)$ \\
\hline 6 consultations ${ }^{*}$, tests, vaccine against tetanus and postpartum care & 36 & 31.3 & 17 & 10.2 & 0.000 & $4.02(2.04-8.01)$ \\
\hline Blood pressure, weight and fundal height in all the consultations & 109 & 94.7 & 144 & 86.2 & 0.020 & $2.90(1.07-8.26)$ \\
\hline Guidance: nutrition and warning signs according to the stage of pregnancy & 99 & 86.0 & 56 & 33.5 & 0.000 & $12.26(6.36-23.94)$ \\
\hline Complete clinical history and HIV counselling & 7 & 6.0 & 0 & 0 & 0.001 & - \\
\hline
\end{tabular}

\section{Discussion}

For obtaining the data used for evaluating the structure, this study used interviews with the managers of the Health Centers, who may not have been totally impartial in relation to their own services. In addition, the process data was obtained based on the records in the pregnant women's health records, but it is known 
some actions may be carried out without being recorded. These aspects, therefore, constitute limitations on the present study and must be considered in interpreting the results obtained.

Regarding the human resources, differences were observed in the training of the doctors and the nurses of the UBS and USF, as were differences relative to the participation of other professionals from the health area in the care of the pregnant women. The small number of centers (eight UBS and eight UFS), however, did not allow evaluation as to whether these differences observed are reflected or not in the process of prenatal care. It was observed that, generally speaking, in the UBS the attendance is centered on the medical professionals, while in the USF the nurse consultations were more incorporated, this fact being related to the change in the nurse's work process promoted by the Family Health Strategy, which brings the nurses closer to the care, based on the elaboration of care protocols which support them ${ }^{(10)}$.

With regard to the physical resources, there were no differences between the UBS and the USF. Equipment and instruments for care for the pregnant women were, in general, available in both the models of care. The only aspect that stands out is relative to the presence of the Technical Manual on pre-natal care, recently published by the Department of Health of the State of São Paulo(8), which was found much more frequently in the USF, probably as a result of the need for up-to-date protocols for supporting the nurse consultations.

All the tests recommended to be carried out in the first and third trimesters are available in the municipality, including in adequate quantities. Although coverage in the first trimester was over $94.0 \%$ in the two services, in the third - even taking into account the recommendation or not for repeating them - the coverage was markedly inferior, especially in the UBS, varying from $55.0 \%$ to $79.6 \%$. In a study on pre-natal assessment undertaken in a mid-size municipality in the metropolitan region of São Paulo, a number of hypotheses were raised to explain the low coverage of tests in the third trimester: the health professionals are used to requesting the tests only in the first consultation, and many stop requesting them again close to the thirtieth week of the pregnancy: also, some women do not do the tests a second time despite being invited to ${ }^{(11)}$. These hypotheses may also explain what happened in the present study.

It was ascertained in a general way that the due importance was not given to the repetition of those routine pre-natal tests which were undertaken less in the third trimester, both in the USF and the UBS, although with a worse result in this latter model of care. The important role that these tests play in tracking illnesses or conditions that have perinatal repercussions should be highlighted - these include gestational diabetes, mother-fetus blood incompatibility and pregnancyassociated asymptomatic bacteriuria, as well as syphilis, Hepatitis B, toxoplasmosis and AIDS, where there is the possibility of vertical transmission.

The importance, especially concerning congenital syphilis, is beyond question, not just for Botucatu but for Brazil: this condition is considered a clear marker of quality health care in the pre-natal stage, as its diagnosis and treatment can be undertaken during the pregnancy in primary health care services. This means that with the results obtained in this work, one can question the quality of the pre-natal care provided in the municipality, as between 10 and $20 \%$ of the pregnant women were not tested for syphilis at the end of their pregnancy.

Another indicator of the quality of the pre-natal care process with very negative performance was that obtained in the evaluation of the carrying-out of breast examinations, which was little-done in both models: little more than a third of the pregnant women had this procedure. It is therefore considered that opportunities were lost, not only for identifying possible changes requiring treatment(12), but also for evaluating the mammillary characteristics, and for offering guidance regarding care of the breasts and breast-feeding. This negative situation does not differ from that found in a study made in the southern region of Brazil, in a municipality of the same size(13). Nevertheless, it is worrying to observe that the values obtained were below those ascertained in 2004 and 2008 in the same municipality ${ }^{(14)}$.

The ultrasound examination is not included as a basic, routine procedure recommended by the PHPN for all low risk pregnancies, but the Department of Health of the State of São Paulo recommends that it be undertaken once or twice, depending on the feasibility. In the early stages of the pregnancy, this is for tracking chromosomal abnormalities and/or at between 20 and 24 weeks, for evaluation of fetal morphology ${ }^{(8)}$. In contrast to the guidance of the MS, the coverage in Botucatu was high: over $90 \%$ of the pregnant women in both the models had at least one ultrasonography during their pregnancy. Such high coverage may be attributed to the fact that the clientele values - and frequently, requests - this examination. One should ask, however, why it is that simpler examinations, of proven efficiency, 
such as vaccination, breast examination and dental care, did not have equally high coverage. This fact - of lower coverage for soft technology actions, and high coverage of more expensive examinations with hard technology has been observed in Brazil before ${ }^{(15)}$.

Dental care, which is essential in pre-natal care, was infrequent in both care models, even though there were dentists in all the Health Centers, so an evaluation of the possible causes is worthwhile. Were there problems in providing enough of these professionals, or in their distribution in the services studied, or was there difficulty in incorporating oral health into pre-natal care? It falls to future studies to check these hypotheses, and the use of the qualitative method is recommended, such that the health professionals' and pregnant women's values and attitudes regarding this specific action may be investigated. At any event, this may be indicated as an important primary health care problem in the municipality of Botucatu, because various studies have shown a correlation between extensive periodontal disease and low birth weight ${ }^{(16)}$.

There is no evidence of risk to the fetus when the pregnant woman is immunized with toxoids, polysaccharide or conjugate vaccines, or vaccines containing dead virus. Specifically in relation to the anti-tetanus vaccine, which is recommended nationwide for maternal protection and prevention of neonatal tetanus ${ }^{(17)}$, the coverage obtained in the UBS and USF was below the expected, taking into account that this immunobiological was always available, and that the great majority of the women had more than six prenatal consultations. More important still is the fact that in Botucatu, the entire primary care system, including the vaccination rooms, is computerized, allowing the control of the doses administered and the pregnant women who did not attend.

The recording of the clinical history was considered to be complete when all its areas had been filled out. This form must be kept in the patient's health records, with an identical copy attached to the pregnant woman's pre-natal card. In the present study, the situation of the USF where this information was collected was more favorable than that of the UBS. It stands out that the health professionals often undervalue the systematic and organized recording of information in the patient's health records, despite these being characterized as a document which supports good care and is fundamental in ethical or legal situations - representing security for the health professional as much as the clientele(11). Perhaps due to the greater need for the nurses to protect themselves legally in carrying out the pre-natal consultations, this instrument was filled out completely more frequently in the USF, where the percentage of nursing consultations was higher.

On analyzing the synthesis indicator of the process of pre-natal care recommended by the PHPN, which covers undertaking six consultations, tests in the first and third trimesters, vaccination against tetanus and postpartum care, the coverage in the USF was low $(31.3 \%)$, but still three times higher than in the UBS $(10.2 \%)$. Carrying out this set of actions should be valued more, as it represents the minimum procedures for adequate pre-natal care, and it deserves to be stressed that every pregnant woman has the right to them, so as to obtain decent, quality care ${ }^{(7)}$. The individual analysis of the components of this synthesis indicator evidences a significant difference between the USF and the UBS for the examinations alone. The situation found in the USF of Botucatu is better than that obtained in a study undertaken in the city of São Paulo, which took into account similar indicators and had a favorable result in only $7.7 \%$ of cases ${ }^{(18)}$.

Evaluation of pre-natal care considering the women's socio-demographic aspects, and based on quantitative indicators, is frequent in the literature ${ }^{(19-20)}$. This is not what is observed when one investigates quality indicators. In the present investigation, a further two synthesis indicators proposed (clinical history filled out and counselling prior to the collection of the sample for HIV testing, and guidance on pre-natal nutrition and warning signs according to the stage of the pregnancy), were also significantly more present in the USF. This fact is relevant because these may indicate a difference in the quality of the pre-natal consultations.

\section{Conclusions}

Generally speaking, the pre-natal care of the USF was better than that of the UBS. However, the low rates of coverage of basic actions, feasible in both models of health care, are worrying and demand urgent actions from the managers and health professionals involved in the pre-natal care in the municipality studied.

Backed by the present study's results, it falls to the managers to intervene, such as through: encouraging the UBS nurses to carry out the pre-natal consultations for low risk pregnancies; actions for raising the nurses' awareness regarding the importance of recording information in the health records; extending educational group activities and creating a proposal for continuing 
education for the health professionals who work in Primary Care, thus seeking to ensure the effective undertaking of the basic procedures called for by the Ministry of Health and the State and Municipal Health Departments, and which are essential for the pre-natal care.

\section{References}

1. Costa AM, Guilhem D, Walter MIM. Atendimento a gestantes no Sistema Único de Saúde. Rev Saúde Pública. 2005;5(39):768-74.

2. Caldeira AP, Oliveira RM, Rodrigues OA. Qualidade da assistência materno-infantil em diferentes modelos de Atenção Primária. Ciênc Saúde Coletiva. 2010;15 Suppl 2:3139-47.

3. Ministério da Saúde (BR). Secretaria de Atenção à Saúde. Departamento de Atenção Básica. Política Nacional de Atenção Básica. Brasília (DF): Ministério da Saúde; 2012.

4. Figueiredo PP, Lunardi Filho WD, Lunardi VL, Pimpão FD. Infant mortality ans prenatal care: contributions of the clinic in the light of Canguilhem and Foucault. Rev. Latino-Am. Enfermagem. 2012;20(1):201-10.

5. Donabedian A. The quality of care. How can it be assessed? JAMA. 1988;260(12):1743-48. 6. Ministério da Saúde (BR). Secretaria de Atenção à Saúde. Departamento de Ações Programáticas Estratégicas. Política Nacional de Atenção Integral à Saúde da Mulher: princípios e diretrizes. Brasília (DF): Ministério da Saúde; 2004.

7. Ministério da Saúde (BR). Secretaria Executiva. Programa de Humanização do Parto: Humanização no Pré-natal e Nascimento. Brasília (DF): Ministério da Saúde; 2002. 8. Secretaria do Estado da Saúde (SP). Atenção à gestante e puérpera no SUS-SP: manual técnico do pré-natal e puerpério. São Paulo (SP): Secretaria de Estado da Saúde; 2010.

9. Instituto Brasileiro de Geografia e Estatística (IBGE). IBGE cidades. Botucatu. [acesso 14 set 2012] Disponível em: http://www.ibge.gov.br/cidadesat/link. php?codmun $=350750$

10. Parada CMGL. Avaliação da assistência pré-natal e puerperal desenvolvidas em região do interior do Estado de São Paulo em 2005. Rev Bras Saúde Mater Infant. 2008;8(1):113-24.

11. Barbosa MA, Fernandes RAQ. Evaluation of prenatal care in low risk pregnancies in the city of Francisco Morato - SP. Online Braz J Nurs [internet]. 2008 [acesso 14 set 2012];7(3) Disponível em: http:// www.objnursing.uff.br/index.php/nursing/article/ view/j.1676-4285.2008.1861/398

12. Naughton MJ, Ellis M. I'm pregnant and I have breast cancer. BMC Câncer. 2007;7:93-4. doi: 10.1186/14712407-7-93.

13. Gonçalves CV, Dias da Costa JS, Duarte G, Marcolin AC, Garlet G, Sakai AF, et al. Exame clínico das mamas em consultas de pré-natal: análise da cobertura e de fatores associados em município do Rio Grande do Sul, Brasil. Cad Saúde Pública. 2008;24(8):1783-90. 14. Fonseca CRB, Strufaldi MWL, Carvalho LR, Puccini RF. Risk factors for low birth weight in Botucatu city, SP state, Brazil: a study conducted in the public health system from 2004 to 2008 BMC Res Notes. 2012;5:60. doi:10.1186/1756-0500-5-60.

15. Gonçalves CV, Dias da Costa JS, Duarte G, Marcolin AC, Velleca e Lima LC, Garlet G, et al. Avaliação da frequência de realização do exame físico das mamas, da colpocitologia cervical e da ultrassonografia obstétrica durante a assistência pré-natal. Uma inversão de valores. Rev Assoc Med Bras. 2009;55(3):290-5. 16. Cruz SS, Costa MCN, Gomes Filho IS, Vianna MIP, Santos CT. Doença periodontal materna como fator associado ao baixo peso ao nascer. Rev Saúde Pública. 2005;39(5):782-7.

17. Bricks LF. Vaccines in pregnancy: a review of their importance in Brazil. Rev Hosp Clín. 2003;58(5):263-74. 18. Succi RCM, Figueiredo EN, Zanatta LC, Peixe MB, Rossi MB, Vianna LAC. Evaluation of prenatal care at basic health units in the city of São Paulo. Rev. Latinoam. Enfermagem 2008; 16(6):986-92.

19. Tran TK, Gottvall K, Nguyen HD, Ascher H, Petzold M. Factos associated with antenatal care adequacy in rural and urban contexts - results from two health and demographic surveillance sites in Vietnam. BMC Health Services Res. 2012;12:40. doi:10.1186/1472-6963-12-40.

20. Hollowell J, Oakley L, Kurinczuk JJ, Brocklehurst P, Gray R. The effectiveness of antenatal care programmes to reduce infanti mortality and preterm birth in socially disadvantaged and vulnerable women in high income countries: a systematic review. BMC Pregnancy Childbirth. 2011;11:13. doi: 10.1186/1471-2393-11-13. 